\title{
An efficient method for computing the binding energy of an adsorbed molecule within a periodic approach. The application to vinyl fluoride at rutile $\mathrm{TiO}_{2}(110)$ surface.
}

\author{
J. Scaranto ${ }^{a, * 1}$, G. Mallia ${ }^{\text {b,* }}$, N. M. Harrison ${ }^{b, c}$ \\ a Dipartimento di Chimica Fisica, Università Ca' Foscari di Venezia, Dorsoduro \\ 2137, I-30123 Venezia, Italy \\ b Thomas Young Centre, Department of Chemistry, Imperial College London, \\ South Kensington London SW7 2AZ, UK \\ ${ }^{\mathrm{c}}$ Daresbury Laboratory, Daresbury, Warrington, WA4 4AD, UK
}

\begin{abstract}
A model for investigating surface adsorption in the limit of low coverage within a periodic supercell formalism is described. The model facilitates the analysis of the contributions to the adsorption energy in terms of interaction, distortion and binding constants defined between nearest and next nearest adsorbed molecules; both direct and surface-mediated effects are considered. As an example the adsorption of vinyl fluoride at the rutile $\mathrm{TiO}_{2}(110)$ surface is studied.
\end{abstract}

Key words: Adsorption energetics, periodic approach, vinyl fluoride, titanium dioxide, oxides

\section{Introduction}

The adsorption process involves the interaction of one or more molecules with a surface and one of the fundamental characteristics of the process is the adsorption energy, $\mathrm{E}_{\mathrm{ads}}$, which can be measured by calorimetric techniques

1 Current address: Chemical \& Biological Engineering Department, University of Wisconsin-Madison, 1415 Engineering Drive, Madison, WI, 53706, USA

* Corresponding authors: scaranto@wisc.edu, g.mallia@imperial.ac.uk 
or can be estimated from TPD (temperature programmed desorption) measurements [1]. The experimentally determined $\mathrm{E}_{\mathrm{ads}}$ may be compared to a computed binding energy, BE, which is defined as:

$$
\mathrm{BE}=\mathrm{E}_{\mathrm{sys}}-\left(\mathrm{E}_{\mathrm{mol}}+\mathrm{E}_{\mathrm{sur}}\right)
$$

where $\mathrm{E}_{\mathrm{sys}}$ is the computed total energy and the suffices mol, sur and sys indicate the molecule, the surface and the adsorbate-substrate system, respectively. A negative (positive) BE means that the adsorption is a favourable (unfavourable) process with respect to the clean surface and an isolated molecule. In studies of inter-molecular interactions, $\mathrm{BE}$ is variously referred to as the stabilisation [2-5], total interaction [6-8], total bond [9-12] or bond dissociation [13-16] energy. BE can be separated into two contributions: the distortion energy, $\mathrm{E}_{\mathrm{dis}}$, and the interaction energy, $\mathrm{E}_{\mathrm{int}}[17-22]$;

$$
\mathrm{BE}=\mathrm{E}_{\mathrm{dis}}+\mathrm{E}_{\mathrm{int}}
$$

In turn, $\mathrm{E}_{\mathrm{dis}}$ can be split into the distortion energy of the surface $\mathrm{E}_{\mathrm{dis}}^{\mathrm{sur}}$ and that of the molecule $\mathrm{E}_{\text {dis }}^{\text {mol }}$ :

$$
\mathrm{E}_{\mathrm{dis}}=\mathrm{E}_{\mathrm{dis}}^{\mathrm{sur}}+\mathrm{E}_{\mathrm{dis}}^{\mathrm{mol}}
$$

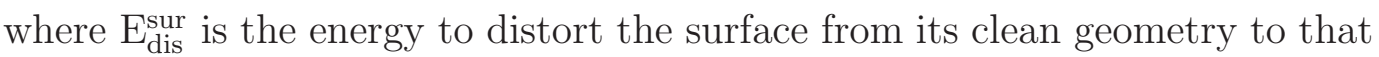
adopted after adsorbtion:

$$
\mathrm{E}_{\mathrm{dis}}^{\mathrm{sur}}=\mathrm{E}_{\mathrm{sur} \mid \mathrm{sys}}-\mathrm{E}_{\mathrm{sur}}
$$

(being $\mathrm{E}_{\text {sur|sys }}$ the energy of the surface at the geometry adopted in the adsorbatesubstrate system and $E_{\text {sur }}$ the energy of the clean surface) and $E_{\text {dis }}^{m o l}$ is the energy to distort the molecule from its gas phase equilibrium geometry to the geometry obtained after adsorption on the surface:

$$
\mathrm{E}_{\mathrm{dis}}^{\mathrm{mol}}=\mathrm{E}_{\mathrm{mol} \mid \mathrm{sys}}-\mathrm{E}_{\mathrm{mol}}
$$

$\mathrm{E}_{\mathrm{dis}}$ is variously referred to as the deformation $[2,3,6,9,17,23-27]$, relaxation $[4,5,8,28]$ or preparation $[10-16,29]$, energy.

Accordingly, $\mathrm{E}_{\text {int }}$ is defined as

$$
\mathrm{E}_{\text {int }}=\mathrm{E}_{\mathrm{sys}}-\left(\mathrm{E}_{\mathrm{mol} \mid \mathrm{sys}}+\mathrm{E}_{\mathrm{sur} \mid \mathrm{sys}}\right)
$$

and it is the component of $\mathrm{E}_{\text {ads }}$ which does not contain effects of the geometrical relaxation; that is, the interaction between fragments already distorted 
to the geometries of the adsorbate-substrate system. Unfortunately the terms "binding energy" and "interaction energy" are often used ambiguously in the literature, as discussed in Ref. [4].

The separation of $\mathrm{BE}$ into $\mathrm{E}_{\mathrm{dis}}$ and $\mathrm{E}_{\text {int }}$ is a useful analytical tool for several reasons:

(1) It is often the case that physical quantities that characterise the adsorption process are correlated to either $\mathrm{E}_{\text {dis }}$ or $\mathrm{E}_{\text {int }}$ more strongly than they are to $\mathrm{E}_{\mathrm{ads}}$, as it has been observed for the adsorbate-substrate charge transfer, which is roughly linear correlated to $\mathrm{E}_{\text {int }}$ and not to $\mathrm{BE}[6]{ }^{2}$

(2) For a specific system, the geometry modification upon the adsorption can be very significant for the ability of the molecule to interact with the surface $[6,27]$, then $\mathrm{E}_{\text {dis }}$ is a useful indicator to assess this contribution to BE.

(3) When investigating chemical reactivity of a set of molecules on different substrates, the separate analysis of $\mathrm{E}_{\mathrm{int}}$ and $\mathrm{E}_{\mathrm{dis}}$ is convenient in order to analyse trends $[18,21,22,27]$.

(4) If a localised atomic orbital scheme is used to compute the energetics, BE is affected by the basis set superposition error (BSSE), which corresponds to an artificial increase in the calculated stability of the supersystem because the basis set of the supersystem is larger than that used for the component subsystems. In order to correct for the BSSE, the counterpoise (CP) method maybe used, which has been described elsewhere for a cluster model of the surface [30-32]. In this case, the separation of the $\mathrm{BE}$ into $\mathrm{E}_{\text {int }}$ and $\mathrm{E}_{\mathrm{dis}}$ is crucial from a computational point of view: the BSSE is related only to $E_{\text {int }}$, since $E_{\text {dis }}$ is defined with respect to energies that have to be calculated in the same basis set (see Eqs 4,5). The $\mathrm{CP}$-corrected interaction energy, $\mathrm{E}_{\mathrm{int}}^{\mathrm{C}}$, is:

$$
\mathrm{E}_{\mathrm{int}}^{\mathrm{C}}=\mathrm{E}_{\mathrm{int}}+\mathrm{BSSE}=\mathrm{E}_{\mathrm{sys}}-\left(\mathrm{E}_{\mathrm{mol} \mid \mathrm{sys}}^{\mathrm{G}}+\mathrm{E}_{\mathrm{sur} \mid \mathrm{sys}}^{\mathrm{G}}\right)
$$

where $\mathrm{E}_{\mathrm{mol} \mid \mathrm{sys}}^{\mathrm{G}}$ and $\mathrm{E}_{\mathrm{sur|sys}}^{\mathrm{G}}$ are the energies of the molecule and of the surface both calculated respectively in the presence of the "ghosted atoms" of the surface and of the molecule (i.e. including the extra basis set of

2 For instance, in the adsorption of three probe molecules, namely pyridine, acetonitrile and carbon monoxide, both on amorphous $\mathrm{B}_{2} \mathrm{O}_{3}-\mathrm{SiO}_{2}$ and on $\gamma-\mathrm{Al}_{2} \mathrm{O}_{3}$, the $\mathrm{BE}$ and the adsorbate-substrate charge transfer $\Delta q$ have been computed. Although $\mathrm{BE}$ is not strongly related to $\Delta q$, there is a rough linear correlation between $\mathrm{E}_{\text {int }}$ and $\Delta q$. In turn, the charge transfer is itself strongly correlated to the infrared frequency shift upon adsorption and so an understanding of $\mathrm{E}_{\text {int }}$ (and the processes which contribute to it) is important for the prediction of frequency shifts: the larger $\mathrm{E}_{\text {int }}$, the higher the charge transfer and the frequency shift [6]. 
the surface or the molecule). The BSSE is positive and equal to:

$$
\mathrm{BSSE}=\left(\mathrm{E}_{\mathrm{mol} \mid \mathrm{sys}}-\mathrm{E}_{\mathrm{mol} \mid \mathrm{sys}}^{\mathrm{G}}\right)+\left(\mathrm{E}_{\mathrm{sur} \mid \mathrm{sys}}-\mathrm{E}_{\mathrm{sur} \mid \mathrm{sys}}^{\mathrm{G}}\right)
$$

Taking into account the $\mathrm{BSSE}$, the $\mathrm{CP}$-corrected binding energy, $\mathrm{BE}^{\mathrm{C}}$, is $[30,32-34]$ :

$$
\begin{gathered}
\mathrm{BE}^{\mathrm{C}}=\mathrm{E}_{\text {int }}^{\mathrm{C}}+\mathrm{E}_{\text {dis }}= \\
\mathrm{E}_{\mathrm{sys}}-\left(\mathrm{E}_{\mathrm{mol} \mid \mathrm{sys}}^{\mathrm{G}}+\mathrm{E}_{\mathrm{sur} \mid \mathrm{sys}}^{\mathrm{G}}\right)+\left(\mathrm{E}_{\mathrm{mol} \mid \text { sys }}-\mathrm{E}_{\mathrm{mol}}\right)+\left(\mathrm{E}_{\mathrm{sur} \mid \mathrm{sys}}-\mathrm{E}_{\mathrm{sur}}\right)
\end{gathered}
$$

(5) The periodic representation of adsorption introduces any additional complexity. Modelling the surface as a slab periodic in two dimensions with a suitable supercell involves adsorbing a periodic array of molecules to the surface. Within the monolayer of molecules there will be inter-molecular interactions which vary with the coverage considered. The lateral moleculemolecule effects can be evaluated conveniently by further exploiting the splitting of $\mathrm{BE}$ into $\mathrm{E}_{\text {int }}$ and $\mathrm{E}_{\text {dis }}$. This issue is described in detail below (Sec. 2.3).

(6) Defining $E_{\text {int }}$ and $E_{\text {dis }}$, a model based on the interaction of nearest and next-nearest neighbouring molecules can be developed for extrapolating the adsorption energy to the very low coverage (adsorption of an isolated molecule) more conveniently than the extrapolation of $\mathrm{E}_{\mathrm{ads}}$, due to the presence of the interaction of the adsorbed molecules at the final geometry in the adsorbate-substrate system. The model requires the denition of a set of effective interaction parameters, which model the lateral interactions, and can be used conveniently in model calculations of the surface thermodynamics.

The aim of this paper is to provide a detailed and meaningful description of the procedure ${ }^{3}$ already successfully applied (partly or completely) to investigate the adsorbate-substrate interaction between $\mathrm{TiO}_{2}$ and some molecules such as $\mathrm{CH}_{2} \mathrm{CHF}[35,36]$ and $\mathrm{CO}[35,37]$. This article allows to have a consistent description of the adsorption energetics in terms not only of the adsorbatesubstrate interaction but also of the inter-molecular ones.

The paper is organised as follows. The procedure for studying adsorption within the periodic approach is discussed in Sec 2, where the direct and surfacemediated effects between molecules are identified. Results for the adsorption of $\mathrm{CH}_{2} \mathrm{CHF}$ on rutile(110) are presented in Sec. 3 and we summarise the conclusions of this work in Sec. 4.

$\overline{3}$ The proposed model can be applied independently of the quantum-mechanical method, the basis set types and quality. 


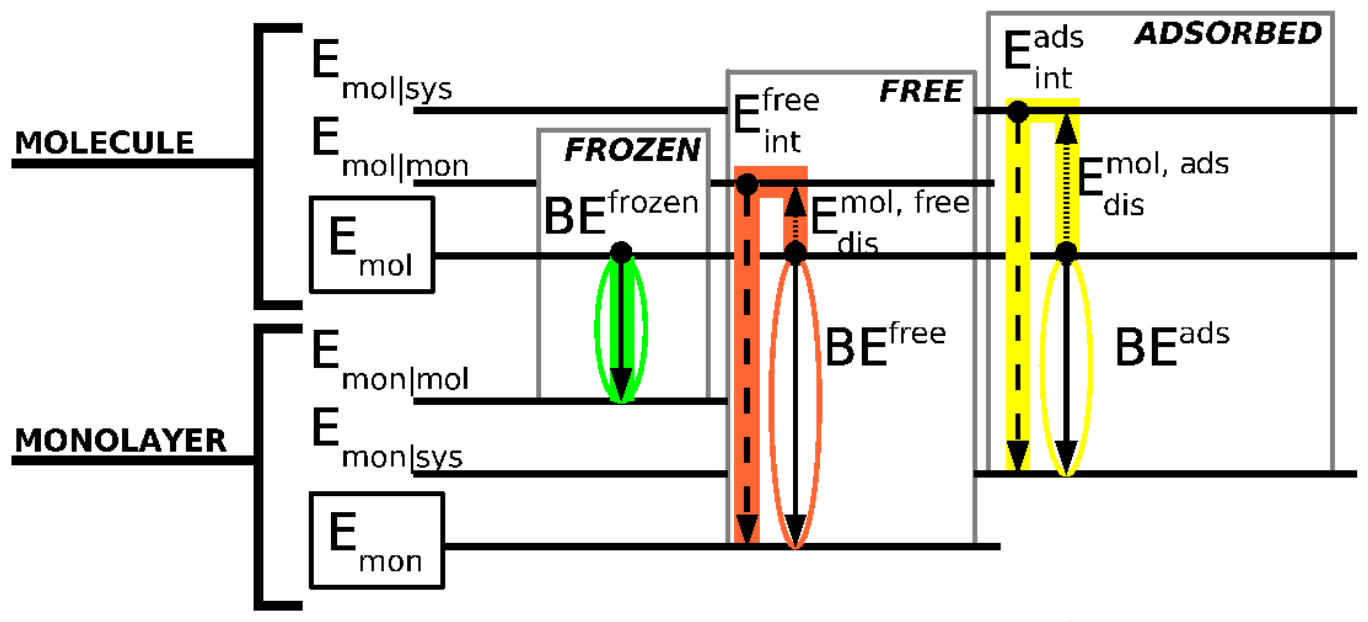

Fig. 1. (Colour online) The interaction (dashed arrow), distortion (dotted arrow) and binding (continuous arrow) energies of the frozen (green), the free (orange) and the adsorbed (yellow) monolayer with respect to the isolated molecules are displayed from left to right.

\section{A periodic model of nearest and next nearest adsorbed molecules}

In this section, the formation of the periodic monolayer of molecules will be firstly considered and the lateral effects between the molecules will be analysed. Then, the model for the study of the adsorption by means of a periodic scheme is presented.

\subsection{The binding energy of a monolayer with respect to the isolated molecule}

Within the slab approach, the molecule at the surface is repeated periodically in a monolayer which has the same periodicity of the two-dimensional slab cell. On the basis of the geometry of the molecule, three different cases can be identified:

(1) frozen monolayer, in which each molecule adopts the geometry of the isolated molecule;

(2) free monolayer, where a relaxation of internal coordinates is allowed;

(3) adsorbed monolayer, the monolayer adopts the geometry of the adsorbed system.

This classification separates the variation of the geometry of the molecule with respect to the isolated limit due lateral interactions from variation due to interaction with the surface (see Fig. 1). The effects of the neighbouring molecules can be assessed by calculating the binding energy of a molecule arranged in a monolayer. This quantity is generally reported as lateral energy. 
The BE of the frozen monolayer with respect to an isolated molecule is an interaction energy, as no distortion of the molecules is allowed.

$$
\mathrm{BE}^{\text {frozen }}=\mathrm{E}_{\mathrm{int}}^{\text {frozen }}=\mathrm{E}_{\mathrm{mon} \mid \mathrm{mol}}-\mathrm{E}_{\mathrm{mol}}
$$

with $\mathrm{E}_{\mathrm{mon} \mid \mathrm{mol}}$ the energy of a monolayer constructed from molecules which have the geometry of the isolated molecule. By constant in the free monolayer, the distortion is given by:

$$
\mathrm{E}_{\mathrm{dis}}^{\text {free }}=\mathrm{E}_{\mathrm{mol} \mid \mathrm{mon}}-\mathrm{E}_{\mathrm{mol}}
$$

with $\mathrm{E}_{\text {mol|mon }}$ the energy of a molecule at the optimised geometry of the monolayer. The binding energy of the free monolayer with respect to an isolated molecule is

$$
\mathrm{BE}^{\text {free }}=\mathrm{E}_{\text {int }}^{\text {free }}+\mathrm{E}_{\mathrm{dis}}^{\text {free }}=\mathrm{E}_{\mathrm{mon}}-\mathrm{E}_{\mathrm{mol}}
$$

where

$$
\mathrm{E}_{\text {int }}^{\text {free }}=\mathrm{E}_{\mathrm{mon}}-\mathrm{E}_{\mathrm{mol} \mid \mathrm{mon}}
$$

Analogously, the distortion, the interaction and the binding energy of the adsorbed monolayer with respect to an isolated molecule are the following:

$$
\begin{aligned}
& \mathrm{E}_{\text {dis }}^{\text {adsorbed }}=\mathrm{E}_{\text {mol|sys }}-\mathrm{E}_{\mathrm{mol}} \\
& \mathrm{E}_{\text {int }}^{\text {adsorbed }}=\mathrm{E}_{\mathrm{mon} \mid \text { sys }}-\mathrm{E}_{\mathrm{mol} \mid \mathrm{sys}} \\
& \mathrm{BE}^{\text {adsorbed }}=\mathrm{E}_{\text {int }}^{\text {adsorbed }}+\mathrm{E}_{\text {dis }}^{\text {adsorbed }}=\mathrm{E}_{\mathrm{mon} \mid \text { sys }}-\mathrm{E}_{\mathrm{mol}}
\end{aligned}
$$

2.2 The binding energy of the monolayer-surface system with respect to the free monolayer and clean surface

The analysis of surface adsorption is a generalisation of that used widely in molecular studies and discussed in Sec. 1. Then, the three energies can be expressed as it is reported below and sketched in Fig. 2. For simplicity, the adsorption of a single molecule per unit cell is considered. The interaction and the distortion energies are given by:

$$
\begin{aligned}
& \mathrm{E}_{\text {int }}^{\mathrm{P}}=\mathrm{E}_{\mathrm{sys}}-\left(\mathrm{E}_{\text {sur|sys }}+\mathrm{E}_{\text {mon|sys }}\right) \\
& \mathrm{E}_{\text {dis }}^{\mathrm{P}}=\mathrm{E}_{\text {dis }}^{\mathrm{P} \text {,sur }}+\mathrm{E}_{\text {dis }}^{\mathrm{P} \text {,mon }}
\end{aligned}
$$


where the superscript ${ }^{\mathrm{P}}$, meaning periodic, has been used to indicate the energies referring to the adsorption of a periodic monolayer. $\mathrm{E}_{\mathrm{dis}}^{\mathrm{sur}}$ and $\mathrm{E}_{\mathrm{dis}}^{\mathrm{mon}} 4$

are the distortion energies for the monolayer and the surface, respectively given by

$$
\begin{aligned}
& \mathrm{E}_{\text {dis }}^{\mathrm{P}, \text { sur }}=\mathrm{E}_{\text {sur|sys }}-\mathrm{E}_{\text {sur }} \\
& \mathrm{E}_{\text {dis }}^{\mathrm{P}, \text { mon }}=\mathrm{E}_{\text {mon } \mid \text { sys }}-\mathrm{E}_{\text {mon }}
\end{aligned}
$$

Accordingly, the binding energy per unit area of the periodic monolayer is:

$$
\mathrm{BE}^{\mathrm{P}}=\mathrm{E}_{\mathrm{int}}^{\mathrm{P}}+\mathrm{E}_{\mathrm{dis}}^{\mathrm{P}}=\mathrm{E}_{\mathrm{sys}}-\left(\mathrm{E}_{\mathrm{sur}}+\mathrm{E}_{\mathrm{mon}}\right)
$$

When investigating systems that do not form periodic overlap, only when the adopted surface cell is large enough to make the lateral effects negligible, $\mathrm{BE}^{\mathrm{P}}$ can compared with the adsorption of a molecule moving from an ideal gas to the surface.

\subsection{The binding energy of the molecule-surface system with respect to the isolated molecule and clean surface}

From a thermodynamical point of view, when moving from the binding energy of the monolayer-surface system to the binding energy of the molecule-surface system the initial state changes, then the energy necessary to form the free monolayer starting from the isolated molecule $\left(\mathrm{BE}^{\text {free }}\right)$ has to be added to $\mathrm{BE}^{\mathrm{P}}$ (see Fig. 3):

$$
\mathrm{BE}=\mathrm{BE}^{\mathrm{P}}+\mathrm{BE}^{\text {free }}=\mathrm{E}_{\text {int }}^{\mathrm{P}}+\mathrm{E}_{\text {dis }}^{\mathrm{P}}+\mathrm{E}_{\text {int }}^{\text {free }}+\mathrm{E}_{\text {dis }}^{\text {free }}
$$

4 The distortion energy of the adsorbed monolayer is also equal to the difference between the binding energies of the adsorbed and free monolayer:

$$
\mathrm{E}_{\text {dis }}^{\mathrm{P} \text {,mon }}=\mathrm{E}_{\mathrm{mon} \mid \mathrm{sys}}-\underline{\mathrm{E}_{\mathrm{mol} \mid \mathrm{sys}}+\mathrm{E}_{\mathrm{mol} \mid \mathrm{sys}}}-\underline{\mathrm{E}_{\mathrm{mol}}+\mathrm{E}_{\mathrm{mol}}}-\underline{\mathrm{E}_{\mathrm{mol} \mid \mathrm{mon}}+\mathrm{E}_{\mathrm{mol} \mid \mathrm{mon}}}-\mathrm{E}_{\mathrm{mon}}(19)
$$

when grouping in pair, $\mathrm{E}_{\text {dis }}^{\mathrm{P} \text {,mon }}$ becomes

$$
\mathrm{E}_{\mathrm{dis}}^{\mathrm{P} \text {,mon }}=\mathrm{E}_{\text {int }}^{\text {adsorbed }}+\mathrm{E}_{\text {dis }}^{\text {adsorbed }}-\mathrm{E}_{\text {dis }}^{\text {free }}-\mathrm{E}_{\text {int }}^{\text {free }}=\mathrm{BE}^{\text {adsorbed }}-\mathrm{BE}^{\text {free }}
$$

and shows that a change in the geometry of the molecule arranged in a monolayer, from the free to the adsorbed one $\left(\mathrm{E}_{\text {dis }}^{\text {adsorbed }}-\mathrm{E}_{\text {dis }}^{\text {free }}\right)$, is associated also with a variation of the interaction energy between the molecules $\left(E_{\text {int }}^{\text {adsorbed }}-E_{\text {int }}^{\text {free }}\right)$. 


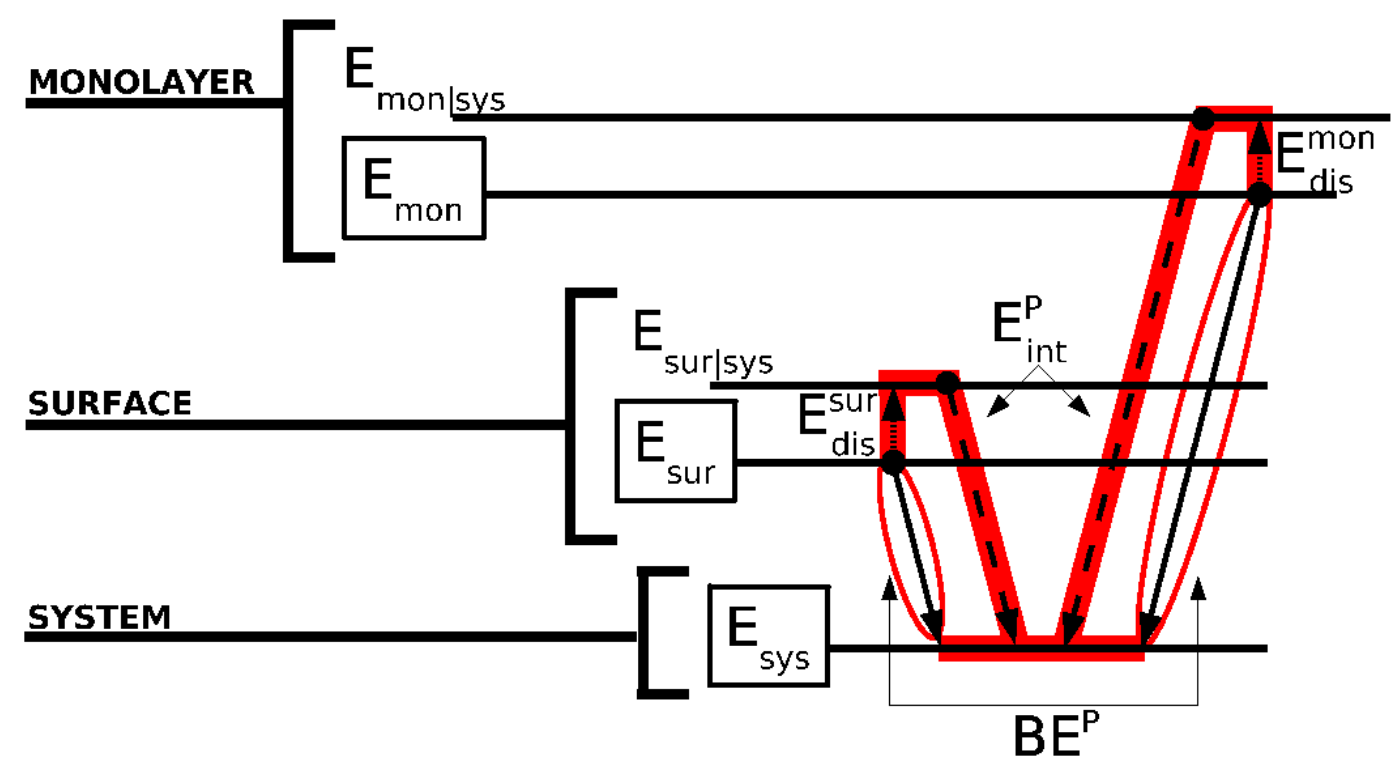

Fig. 2. (Colour online) The interaction, distortion and binding energies of the monolayer-surface system with respect to the free monolayer and clean surface are shown.

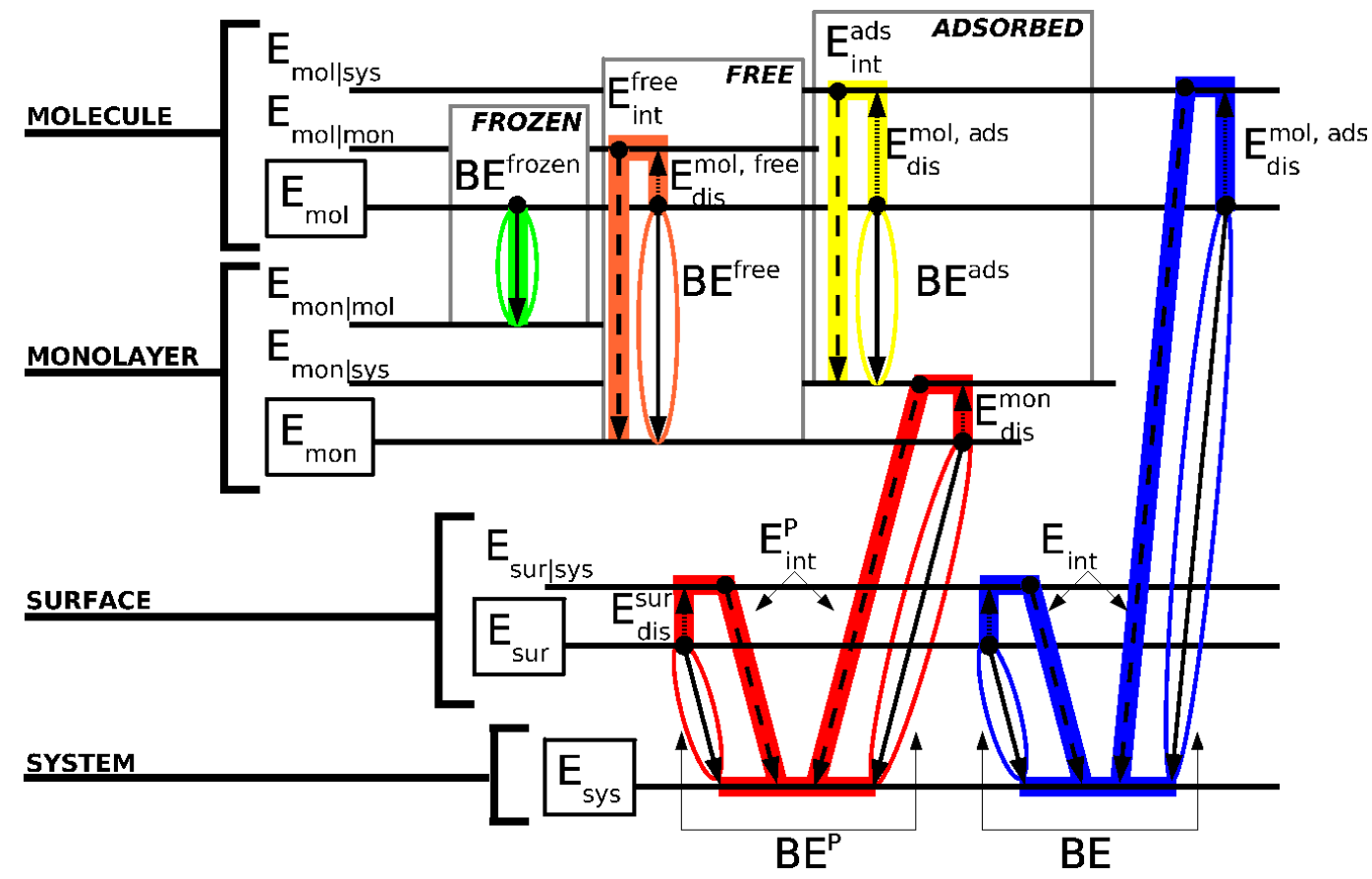

Fig. 3. (Colour online) The interaction (dashed arrow), distortion (dotted arrow) and binding (continuous arrow) energies of the frozen (green), the free (orange) and the adsorbed (yellow) monolayer with respect to the isolated molecules are displayed from top-left to top-right. In the bottom panel the interaction, distortion and binding energies of the monolayer-surface system with respect to the free monolayer and clean surface (red) and of the molecule-surface system with respect to the isolated molecule and clean surface (blue) are shown. 


$$
\mathrm{BE}=\mathrm{E}_{\text {int }}^{\mathrm{P}}+\mathrm{E}_{\text {dis }}^{\mathrm{P}, \text { sur }}+\mathrm{E}_{\text {dis }}^{\mathrm{P}, \text { mon }}+\mathrm{E}_{\text {int }}^{\text {free }}+\mathrm{E}_{\text {dis }}^{\text {free }}
$$

It can that $\mathrm{E}_{\text {dis }}^{\mathrm{P} \text {,mon }}+\mathrm{E}_{\text {int }}^{\text {free }}+\mathrm{E}_{\text {dis }}^{\text {free }}=\mathrm{E}_{\text {int }}^{\text {adsorbed }}+\mathrm{E}_{\text {dis }}^{\text {adsorbed }}$ (see footnote 4 ), therefore

$$
\mathrm{BE}=\mathrm{E}_{\text {int }}^{\mathrm{P}}+\mathrm{E}_{\mathrm{dis}}^{\mathrm{P} \text {,sur }}+\mathrm{E}_{\text {int }}^{\text {adsorbed }}+\mathrm{E}_{\mathrm{dis}}^{\text {adsorbed }}
$$

When grouping the interaction and distortion contribution, it follows that the net interaction and distortion energies are:

$$
\begin{aligned}
& \mathrm{E}_{\text {int }}=\mathrm{E}_{\text {int }}^{\mathrm{P}}+\mathrm{E}_{\text {int }}^{\text {adsorbed }}=\mathrm{E}_{\mathrm{sys}}-\left(\mathrm{E}_{\mathrm{mol} \mid \text { sys }}+\mathrm{E}_{\mathrm{sur} \mid \mathrm{sys}}\right) \\
& \mathrm{E}_{\text {dis }}=\mathrm{E}_{\text {dis }}^{\mathrm{P} \text {,sur }}+\mathrm{E}_{\text {dis }}^{\text {adsorbed }}=\left(\mathrm{E}_{\mathrm{sur} \mid \text { sys }}-\mathrm{E}_{\mathrm{sur}}\right)+\left(\mathrm{E}_{\mathrm{mol} \mid \text { sys }}-\mathrm{E}_{\mathrm{mol}}\right)
\end{aligned}
$$

It is significant for the model that will be described in Sec 2.4 to define the following energies:

- the lateral binding energy, according to Eq. 24:

$$
\mathrm{BE}^{\mathrm{L}}=\mathrm{BE}-\mathrm{BE}^{\mathrm{P}}=\mathrm{BE}^{\text {free }}
$$

- the lateral interaction energy

$$
\mathrm{E}_{\text {int }}^{\mathrm{L}}=\mathrm{E}_{\text {int }}-\mathrm{E}_{\text {int }}^{\mathrm{P}}=\mathrm{E}_{\text {int }}^{\text {adsorbed }}
$$

- the lateral distortion energy

$$
\mathrm{E}_{\mathrm{dis}}^{\mathrm{L}}=\mathrm{E}_{\mathrm{dis}}-\mathrm{E}_{\text {dis }}^{\mathrm{P}}=\mathrm{E}_{\text {dis }}^{\text {free }}+\mathrm{E}_{\text {int }}^{\text {free }}-\mathrm{E}_{\text {int }}^{\text {adsorbed }}
$$

The advantage of the lateral energies $\left(\mathrm{E}_{\mathrm{int}}^{\mathrm{L}}, \mathrm{E}_{\mathrm{dis}}^{\mathrm{L}}\right.$ and $\left.\mathrm{BE}^{\mathrm{L}}\right)$ consists of isolating the direct effects due to the presence of a periodic array of adsorbed molecules, since the surface related energy contributions, which appear in both the net and the periodic energies, cancels out.

\subsubsection{CP-corrected interaction energies}

Analogously to the cluster approach, the interaction energy has to be CPcorrected due to the BSSE (see Sec. 1), when a local basis set is adopted. As concerns the frozen, free and adsorbed monolayer, Equations 10, 13 and 15 respectively become:

$$
\begin{aligned}
& \mathrm{E}_{\text {int }}^{\mathrm{C} \text {,frozen }}=\mathrm{E}_{\mathrm{mon} \mid \mathrm{mol}}-\mathrm{E}_{\mathrm{mol}}^{\mathrm{g}} \\
& \mathrm{E}_{\text {int }}^{\mathrm{C} \text {,free }}=\mathrm{E}_{\mathrm{mon}}-\mathrm{E}_{\mathrm{mol} \mid \mathrm{mon}}^{\mathrm{g}} \\
& \mathrm{E}_{\text {int }}^{\mathrm{C} \text {,adsorbed }}=\mathrm{E}_{\text {mon|sys }}-\mathrm{E}_{\mathrm{mol} \mid \mathrm{sys}}^{\mathrm{g}}
\end{aligned}
$$


where $\mathrm{E}_{\mathrm{mol}}^{\mathrm{g}}, \mathrm{E}_{\mathrm{mol} \mid \mathrm{mon}}^{\mathrm{g}}$ and $\mathrm{E}_{\mathrm{mol} \mid \mathrm{sys}}^{\mathrm{g}}$ are the energy of the isolated molecule and of the molecule at the free and adsorbed monolayer geometries calculated in the presence of the basis sets of the neighbouring molecules.

The interaction energies between the surface and the adsorbed monolayer (Eq. 17) and between the surface and the adsorbed molecule (Eq. 26) have also to be CP-corrected as follows:

$$
\begin{aligned}
& \mathrm{E}_{\text {int }}^{\mathrm{C}, \mathrm{P}}=\mathrm{E}_{\mathrm{sys}}-\left(\mathrm{E}_{\mathrm{sur} \mid \mathrm{sys}}^{\mathrm{G}}+\mathrm{E}_{\mathrm{mon} \mid \mathrm{sys}}^{\mathrm{G}}\right) \\
& \mathrm{E}_{\text {int }}^{\mathrm{C}}=\mathrm{E}_{\mathrm{sys}}-\left(\mathrm{E}_{\mathrm{sur} \mid \mathrm{sys}}^{\mathrm{G}}+\mathrm{E}_{\mathrm{mol} \mid \mathrm{sys}}^{\mathrm{G}}\right)
\end{aligned}
$$

where $\mathrm{E}_{\mathrm{sur} \mid \mathrm{sys}}^{\mathrm{G}}, \mathrm{E}_{\mathrm{mon} \mid \mathrm{sys}}^{\mathrm{G}}$ and $\mathrm{E}_{\mathrm{mol} \mid \mathrm{sys}}^{\mathrm{G}}$ are the energy of the molecule, the monolayer and the surface calculated in the full basis set of the final adsorbate substrate system.

The use of the CP-corrected interaction energies (defined by Equations 3135) into Equations 10, 12, 16, 23, 24, 28 and 29 allows the definition of the corresponding $\mathrm{CP}$-corrected energies: $\mathrm{BE}^{\mathrm{C} \text {,frozen }}, \mathrm{BE}^{\mathrm{C} \text {,free }}, \mathrm{BE}^{\mathrm{C} \text {,adsorbed }}, \mathrm{BE}^{\mathrm{C}, \mathrm{P}}$, $\mathrm{BE}^{\mathrm{C}}, \mathrm{BE}^{\mathrm{C}, \mathrm{L}}$ and $\mathrm{E}_{\text {int }}^{\mathrm{C}, \mathrm{L}}$.

From now on, the superscript ${ }^{\mathrm{C}}$ will be dropped for simplicity, and all the interaction and binding energies assumed to have been CP-corrected.

\subsection{Nearest and Next-Nearest Neighbours Model}

As it has been written above, the adoption of a molecule within a periodic approach is affected by the presence of neighbouring molecules, as a consequence the quantities $\mathrm{E}_{\text {int }}^{\mathrm{L}}, \mathrm{E}_{\text {dis }}^{\mathrm{L}}, \mathrm{BE}^{\mathrm{L}}, \mathrm{E}_{\text {int }}^{\mathrm{P}}, \mathrm{E}_{\text {dis }}^{\mathrm{P}}, \mathrm{BE}^{\mathrm{P}}, \mathrm{E}_{\text {int }}, \mathrm{E}_{\text {dis }}$ and $\mathrm{BE}$ are dependent on the periodicity of the two-dimensional cell of the monolayer. A model based on the interaction of Nearest and Next Nearest Neighbouring molecules is presented in this section in order to study their variation with surface coverage and to isolate 1) the direct and 2) the surface-mediated effects between adsorbed molecules. As concerns the former, the lateral energies can be expressed as follows:

$$
\begin{aligned}
& \mathrm{E}_{\mathrm{int}, \mathrm{n} \times \mathrm{m}}^{\mathrm{L}}=\mathrm{E}_{\text {int, } \mathrm{n} \times \mathrm{m}}^{\text {adsorbed }}=\mathrm{i}_{\mathrm{na}}+\mathrm{i}_{\mathrm{mb}}+2 \mathrm{i}_{\mathrm{na}, \mathrm{mb}} \\
& \mathrm{E}_{\mathrm{dis}, \mathrm{n} \times \mathrm{m}}^{\mathrm{L}}=\mathrm{E}_{\mathrm{dis}, \mathrm{n} \times \mathrm{m}}^{\mathrm{free}}+\mathrm{E}_{\text {int }, \mathrm{n} \times \mathrm{m}}^{\mathrm{free}}-\mathrm{E}_{\text {int, } \mathrm{n} \times \mathrm{m}}^{\text {adsorbed }}=\mathrm{d}_{\mathrm{na}}+\mathrm{d}_{\mathrm{mb}}+2 \mathrm{~d}_{\mathrm{na}, \mathrm{mb}} \\
& \mathrm{BE}_{\mathrm{n} \times \mathrm{m}}^{\mathrm{L}}=\mathrm{BE}_{\mathrm{n} \times \mathrm{m}}^{\text {free }}=\mathrm{b}_{\mathrm{na}}+\mathrm{b}_{\mathrm{mb}}+2 \mathrm{~b}_{\mathrm{na}, \mathrm{mb}}
\end{aligned}
$$

where $\mathrm{n} \times \mathrm{m}$ indicates the periodicity of the monolayer; the translational vectors of the cell are na and $\mathbf{m b}$. The quantities $\mathrm{i}, \mathrm{d}$ and $\mathrm{b}$ are the direct in- 
teraction, distortion and binding constants. The direct interaction constants $i$ are labelled such that $i_{n a}$ and $i_{m b}$ are the interactions between molecules separated solely by na, and $m \mathbf{b}$ respectively, and $i_{n a, m b}$ denotes the diagonal interaction along the vector $(n \mathbf{a}, m \mathbf{b})$, analogously for $\mathrm{d}$ and $\mathrm{b}$.

The surface mediated constants, I, D and B can be likewise defined according to the formulas:

$$
\begin{aligned}
& \mathrm{E}_{\mathrm{int}, \mathrm{n} \times \mathrm{m}}^{\mathrm{P}}=\mathrm{E}_{\mathrm{int}}^{\lim }+\mathrm{I}_{\mathrm{na}}+\mathrm{I}_{\mathrm{mb}}+2 \mathrm{I}_{\mathrm{n} \mathbf{a}, \mathrm{mb}} \\
& \mathrm{E}_{\text {dis, } \mathrm{n} \times \mathrm{m}}^{\mathrm{P}}=\mathrm{E}_{\mathrm{dis}}^{\lim }+\mathrm{D}_{\mathrm{na}}+\mathrm{D}_{\mathrm{mb}}+2 \mathrm{D}_{\mathrm{na}, \mathrm{mb}} \\
& \mathrm{BE}_{\mathrm{n} \times \mathrm{m}}^{\mathrm{P}}=\mathrm{BE}^{\mathrm{lim}}+\mathrm{B}_{\mathrm{na}}+\mathrm{B}_{\mathrm{mb}}+2 \mathrm{~B}_{\mathrm{na}, \mathrm{mb}}
\end{aligned}
$$

where $\mathrm{E}_{\text {int }}^{\lim }, \mathrm{E}_{\text {dis }}^{\lim }$ and $\mathrm{BE}^{\lim }$ are $\mathrm{E}_{\text {int }}, \mathrm{E}_{\mathrm{dis}}$ and $\mathrm{BE}$ in the limiting case of an adsorbed isolated molecule. Concerning the periodic distortion, the equation 40 can be also defined for $\mathrm{E}_{\text {dis,sur }}^{\mathrm{P}}$ and $\mathrm{E}_{\text {dis,mon }}^{\mathrm{P}}$ (see Eqs. 21 and 22), which allows the calculation of $\mathrm{E}_{\mathrm{dis}, \mathrm{sur}}^{\lim }$ and $\mathrm{E}_{\mathrm{dis}, \mathrm{lim}}^{\lim }$ and the corresponding constants.

Accordingly, the net energies can be written as follows:

$$
\begin{aligned}
& \mathrm{E}_{\mathrm{int}, \mathrm{n} \times \mathrm{m}}=\mathrm{E}_{\mathrm{int}}^{\mathrm{lim}}+\mathrm{I}_{\mathrm{na}}+\mathrm{I}_{\mathrm{mb}}+2 \mathrm{I}_{\mathrm{n} \mathbf{a}, \mathrm{mb}}+\mathrm{i}_{\mathrm{na}}+\mathrm{i}_{\mathrm{mb}}+2 \mathrm{i}_{\mathrm{na}, \mathrm{mb}} \\
& \mathrm{E}_{\mathrm{dis}, \mathrm{n} \times \mathrm{m}}=\mathrm{E}_{\mathrm{dis}}^{\mathrm{lim}}+\mathrm{D}_{\mathrm{na}}+\mathrm{D}_{\mathrm{mb}}+2 \mathrm{D}_{\mathrm{na}, \mathrm{mb}}+\mathrm{d}_{\mathrm{na}}+\mathrm{d}_{\mathrm{mb}}+2 \mathrm{~d}_{\mathrm{n} \mathbf{a}, \mathrm{mb}} \\
& \mathrm{BE}_{\mathrm{n} \times \mathrm{m}}=\mathrm{BE} \mathrm{E}^{\mathrm{lim}}+\mathrm{B}_{\mathrm{na}}+\mathrm{B}_{\mathrm{mb}}+2 \mathrm{~B}_{\mathrm{na}, \mathrm{mb}}+\mathrm{b}_{\mathrm{na}}+\mathrm{b}_{\mathrm{mb}}+2 \mathrm{~b}_{\mathrm{na}, \mathrm{mb}}
\end{aligned}
$$

\section{Illustrative application}

\subsection{Computational details}

All calculations have been performed using the CRYSTAL software package [38], based on the expansion of the crystalline orbitals as a linear combination of a basis set consisting of atom centred Gaussian orbitals. The titanium and oxygen atoms are described by a double valence all-electron basis set (an 86-51G* contraction: one $\mathrm{s}$, three sp and one $\mathrm{d}$ shells) and a triple valence (an 8-411G contraction: one s, three sp shells), respectively [39]; the most diffuse sp exponents are $\alpha^{\mathrm{Ti}}=0.598$ and $\alpha^{\mathrm{O}}=0.184 \mathrm{bohr}^{-2}$. The vinyl fluoride molecule, $\mathrm{CH}_{2} \mathrm{CHF}$, has been described using the standard 6-31G** contraction (one s, two sp and one d shells for carbon and fluorine and two s and one p shells for hydrogen) [40]. 
Electron exchange and correlation are approximated using the B3LYP hybrid exchange functional [41], since it has been proven to provide a reliable approach to both the structural properties [42-44] and the electronic structure $[45-51]$.

Further details can be found in [52].

\subsection{Results}

The presented model has been applied to investigation of the adsorption of $\mathrm{CH}_{2} \mathrm{CHF}$ at the $\mathrm{TiO}_{2}$ (110) surface of the rutile phase (see Fig 4) presented in a recent paper [52]. The rutile $\mathrm{TiO} 2(110)$ surface exposes sixfold and fivefold coordinated titanium ions and threefold (planar) and twofold (bridging) coordinated oxygen ions. The optimisation of the adsorbate-substrate system has been carried out by adsorbing the molecule in an initial geometry with its symmetry plane perpendicular to the plane of the surface with the fluorine atom above one fivefold coordinated titanium ion and with one hydrogen atom above one twofold coordinated oxygen ions. This adsorption structure has been previously checked through the comparison between the calculated and observed vibrational frequencies of the molecule [53].

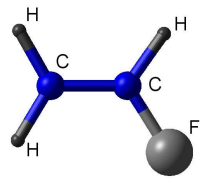

ISOLATED MOLECULE

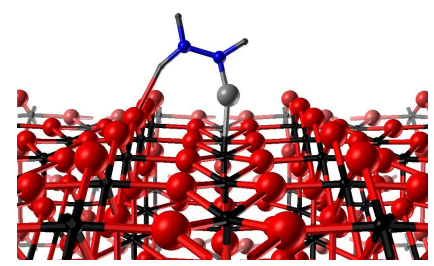

ADSORBATE-SUBSTRATE SYSTEM

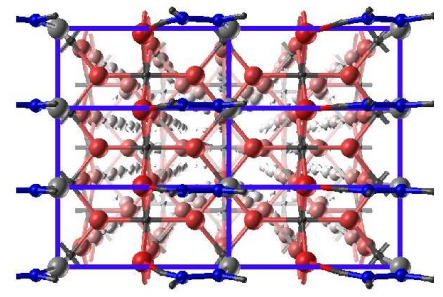

$1 \times 1$

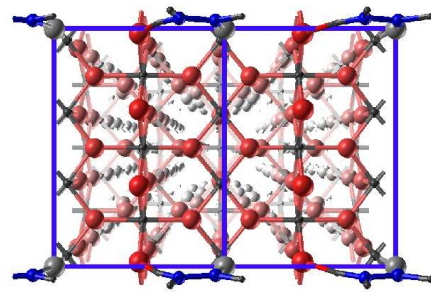

$3 \times 1$

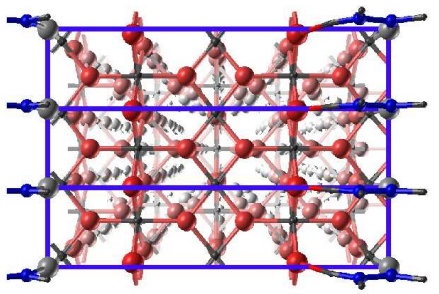

$1 \times 2$

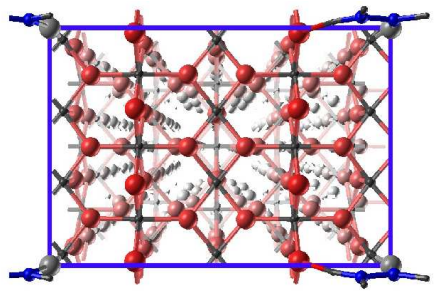

$3 \times 2$

Fig. 4. (Colour online) Isolated vinyl fluoride molecule, 3D representation of adsorbatesubstrate system (outermost layers) and top view of different coverages corresponding to the indicated periodicity.

The interaction, distortion and binding energies have been calculated by using counterpoise method when adopting a periodic approach to simulate the surface. The lattice vectors of the primitive surface cell are $\mathbf{a}=2.995$ and $\mathbf{b}$ $=6.465 \AA$. The interaction, distortion and binding constants are evaluated by 
assuming that $\mathrm{i}_{\mathrm{na}}\left(\mathrm{I}_{\mathrm{na}}, \mathrm{d}_{\mathrm{na}}, \mathrm{D}_{\mathrm{na}}, \mathrm{b}_{\mathrm{na}}\right.$ and $\left.\mathrm{B}_{\mathrm{na}}\right)$ and $\mathrm{i}_{\mathrm{mb}}\left(\mathrm{I}_{\mathrm{mb}}, \mathrm{d}_{\mathrm{mb}}, \mathrm{D}_{\mathrm{mb}}, \mathrm{b}_{\mathrm{mb}}\right.$ and $\left.\mathrm{B}_{\mathrm{mb}}\right)$ can be neglected in the case of $(4 \times 1)$ and $(1 \times 3)$ cells, respectively; in addition, the diagonal constant along the vector $(n \mathbf{a}, m \mathbf{b})$ has been taken into account only in the case of $(1 \times 1)$ and $(2 \times 1)$ cells (see appendix for further detailed explanations).

In Table 1 the interaction, distortion and binding energies are reported. The most interesting feature is the positive value of the net interaction and binding energies for the $(1 \times \mathrm{m})$ periodicities.

In Table 2 the interaction, distortion and binding molecule-molecule constants are given. It is striking the very large direct repulsion of the molecules along the a direction that is attributable to the strong repulsion of the $\pi$ electrons in the $\mathrm{C}=\mathrm{C}$ double bond; then the adsorption for the $(1 \times \mathrm{m})$ systems is not favourable. It is evident that the direct (surface-mediated) lateral effects become negligible faster along the $\mathbf{a}(\mathbf{b})$ direction than along the $\mathbf{b}(\mathbf{a})$ one. Concerning the energies in the limit of an isolated adsorbed molecule, $\mathrm{E}_{\mathrm{int}}^{\mathrm{lim}}$, $\mathrm{E}_{\mathrm{dis}, \mathrm{m}}^{\lim }, \mathrm{E}_{\mathrm{dis}, \mathrm{s}}^{\lim }$ and $\mathrm{BE}^{\lim }$ are equal respectively to $-43.65,7.30,14.51$ and -21.84 $\mathrm{kJ} / \mathrm{mol}$.

\section{Conclusions}

A scheme to study the adsorption energetics within a periodic approach has been presented in order to calculate the binding energy in the case of an isolated adsorbed molecule ( $\left.\mathrm{BE}^{\mathrm{lim}}\right)$, as well as the interaction and the distortion energies $\left(E_{\text {int }}^{\lim }\right.$ and $\left.E_{\text {dis }}^{\lim }\right)$. This model has the advantages to evaluate the mutual effects between adsorbed molecules by means of interaction, distortion and binding constants defined along the periodic direction of the two-dimensional cell adopted to simulate the surface. The scheme also allows to separate the direct and surface-mediated effects between adsorbed molecules at the surface, the former are evaluated through i, d and b, respectively for direct interaction, distortion and binding constant, and the latter through the corresponding surface mediated parameters I, D and B. These constants are also crucial as a starting point for a following Montecarlo simulation, aimed at understanding non-uniform adsorption.

An illustrative application of the model is provided, considering the adsorption of vinyl fluoride at rutile $\mathrm{TiO}_{2}(110)$ surface. It has found a different behaviour of the direct and surface-mediated effects. In fact, the direct (surfacemediated) lateral effects become negligible faster along the a (b) direction than along the $\mathbf{b}(\mathbf{a})$ one. 


\section{Appendix}

The system used for the determination of $\mathrm{i}$ is formed by the following seven equations:

$$
\begin{aligned}
& i_{1 \mathbf{a}}=E_{\text {int }, 1 \times 3}^{\mathrm{L}} \\
& \mathrm{i}_{2 \mathbf{a}}=\mathrm{E}_{\text {int }, 2 \times 2}^{\mathrm{L}}-\mathrm{i}_{2 \mathbf{b}} \\
& \mathrm{i}_{3 \mathbf{a}}=\mathrm{E}_{\text {int }, 3 \times 1}^{\mathrm{L}}-\mathrm{E}_{\text {int }, 4 \times 1}^{\mathrm{L}} \\
& \mathrm{i}_{1 \mathbf{b}}=\mathrm{E}_{\text {int }, 4 \times 1}^{\mathrm{L}} \\
& \mathrm{i}_{2 \mathbf{b}}=\mathrm{E}_{\text {int }, 3 \times 2}^{\mathrm{L}}-\mathrm{i}_{3 \mathbf{a}} \\
& \mathrm{i}_{1 \mathbf{a}, 1 \mathbf{b}}=\left(\mathrm{E}_{\text {int }, 1 \times 1}^{\mathrm{L}}-\mathrm{i}_{1 \mathbf{a}}-\mathrm{i}_{1 \mathbf{b}}\right) / 2 \\
& \mathrm{i}_{2 \mathbf{a}, 1 \mathbf{b}}=\left(\mathrm{E}_{\text {int }, 2 \times 1}^{\mathrm{L}}-\mathrm{i}_{2 \mathbf{a}}-\mathrm{i}_{1 \mathbf{b}}\right) / 2
\end{aligned}
$$

A corresponding set of equations has been used for $d$ and $b$.

The system used for the determination of I and $E_{\text {int }}^{\lim }$ consists of the following eight equations:

$$
\begin{aligned}
& I_{1 \mathbf{a}}=E_{\text {int }}^{\lim }-E_{\text {int }, 1 \times 2}^{P}-I_{2 \mathbf{b}} \\
& I_{2 \mathbf{a}}=E_{\text {int }}^{\lim }-E_{\text {int }, 2 \times 2}^{\mathrm{P}}-\mathrm{I}_{2 \mathbf{b}} \\
& \mathrm{I}_{3 \mathbf{a}}=\mathrm{E}_{\text {int }, 4 \times 1}^{\mathrm{P}}-\mathrm{E}_{\text {int }, 3 \times 1}^{\mathrm{P}} \\
& \mathrm{I}_{1 \mathbf{b}}=\mathrm{E}_{\text {int }}^{\lim }-\mathrm{E}_{\text {int }, 4 \times 1}^{\mathrm{P}} \\
& \mathrm{I}_{2 \mathbf{b}}=\mathrm{E}_{\text {int }, 1 \times 3}^{\mathrm{P}}-\mathrm{E}_{\text {int }, 1 \times 2}^{\mathrm{P}} \\
& \mathrm{I}_{1 \mathbf{a}, 1 \mathbf{b}}=\left(\mathrm{E}_{\text {int }}^{\lim }-\mathrm{E}_{\text {int }, 1 \times 1}^{\mathrm{P}}-\mathrm{I}_{1 \mathbf{a}}-\mathrm{I}_{1 \mathbf{b}}\right) / 2 \\
& \mathrm{I}_{2 \mathbf{a}, 1 \mathbf{b}}=\left(\mathrm{E}_{\text {int }}^{\lim }-\mathrm{E}_{\text {int }, 2 \times 1}^{\mathrm{P}}-\mathrm{I}_{2 \mathbf{a}}-\mathrm{I}_{1 \mathbf{b}}\right) / 2 \\
& \mathrm{E}_{\text {int }}^{\lim }=\mathrm{E}_{\text {int }, 3 \times 2}^{\mathrm{P}}+\mathrm{I}_{3 \mathbf{a}}+\mathrm{I}_{2 \mathbf{b}}
\end{aligned}
$$

The constants $\mathrm{D}$ and $\mathrm{B}$ and the quantities $\mathrm{E}_{\mathrm{dis}}^{\lim }$ and $\mathrm{BE} \mathrm{E}^{\lim }$ are evaluated according the similar set of equations. 


\section{Acknowledgements}

JS is grateful to Prof. S. Giorgianni for interesting discussions. Financial support by PRIN funds (MIUR) is also gratefully acknowledged. GM thanks Dr R. Martinez-Casado for useful comments. In addition, this work made use of the facilities of Imperial College HPC and - via our membership of the UK's HPC Materials Chemistry Consortium funded by EPSRC (EP/F067496) - of HECToR, the UK's national high-performance computing service, which is provided by UoE HPCx Ltd at the University of Edinburgh, Cray Inc and NAG Ltd, and funded by the Office of Science and Technology through EPSRC's High End Computing Programme. 
Table 1

Interaction, distortion and binding energies as a function of the periodicity $(\mathrm{kJ} / \mathrm{mol})$ and the corresponding surface coverage, $\Theta$. The percentage difference $\Delta \%$ of $\mathrm{BE}^{\mathrm{C}}$ with respect the limiting case $(-21.84 \mathrm{~kJ} / \mathrm{mol})$ is also given in the last row of data.

\begin{tabular}{|c|c|c|c|c|c|c|c|c|}
\hline \hline & & \multicolumn{7}{|c|}{ Periodicity } \\
& $1 \times 1$ & $1 \times 2$ & $1 \times 3$ & $2 \times 1$ & $3 \times 1$ & $4 \times 2$ & $2 \times 2$ & $3 \times 2$ \\
\hline$\Theta$ & 1 & $1 / 2$ & $1 / 3$ & $1 / 2$ & $1 / 3$ & $1 / 4$ & $1 / 4$ & $1 / 6$ \\
$\mathrm{E}_{\text {int }}^{\mathrm{C}}$ & -26.35 & -34.86 & -37.37 & -29.25 & -33.23 & -34.88 & -36.08 & -39.49 \\
$\mathrm{E}_{\text {dis }}^{\mathrm{P}, \mathrm{mon}}$ & 4.19 & 4.75 & 5.01 & 4.99 & 5.73 & 6.11 & 5.85 & 6.67 \\
$\mathrm{E}_{\text {dis }}^{\mathrm{P}, \text { sur }}$ & 7.51 & 11.19 & 12.31 & 8.13 & 9.25 & 10.32 & 10.75 & 12.34 \\
$\mathrm{E}_{\text {dis }}$ & 11.70 & 15.94 & 17.32 & 13.12 & 14.98 & 16.43 & 16.60 & 19.01 \\
$\mathrm{BE}^{\mathrm{C}}$ & -14.65 & -18.92 & -20.05 & -16.13 & -18.25 & -18.45 & -19.48 & -20.48 \\
$\mathrm{E}_{\text {int }}^{\mathrm{C}, \mathrm{L}}$ & 41.83 & 40.25 & 39.87 & 3.06 & 1.94 & 1.55 & 1.68 & 0.74 \\
$\mathrm{E}_{\text {dis }}^{\mathrm{L}}$ & -1.38 & -0.66 & -0.51 & -1.04 & -0.86 & -0.77 & -0.41 & -0.23 \\
$\mathrm{BE}^{\mathrm{C}, \mathrm{L}}$ & 40.45 & 39.59 & 39.36 & 2.02 & 1.08 & 0.78 & 1.27 & 0.51 \\
$\mathrm{E}_{\text {int }}^{\mathrm{C}}$ & 15.48 & 5.39 & 2.50 & -26.19 & -31.29 & -33.33 & -34.40 & -38.75 \\
$\mathrm{E}_{\text {dis }}$ & 10.32 & 15.28 & 16.81 & 12.08 & 14.12 & 15.66 & 16.19 & 18.78 \\
$\mathrm{BE}^{\mathrm{C}}$ & 25.80 & 20.67 & 19.31 & -14.11 & -17.17 & -17.67 & -18.21 & -19.97 \\
$\Delta \%$ & -218 & -195 & -188 & -35 & -21 & -19 & -17 & -9 \\
\hline \hline
\end{tabular}

Table 2

Interaction, distortion and binding constants $(\mathrm{kJ} / \mathrm{mol})$

\begin{tabular}{|c|c|c|c|c|c|c|c|}
\hline \hline & $1 \mathbf{a}$ & $2 \mathbf{a}$ & $3 \mathbf{a}$ & $1 \mathbf{b}$ & $2 \mathbf{b}$ & $1 \mathbf{a}, 1 \mathbf{b}$ & $2 \mathbf{a}, 1 \mathbf{b}$ \\
\hline $\mathrm{i}$ & 39.87 & 1.33 & 0.39 & 1.55 & 0.35 & 0.21 & 0.09 \\
$\mathrm{~d}$ & -0.51 & -0.27 & -0.09 & -0.77 & -0.14 & -0.05 & 0.00 \\
$\mathrm{~b}$ & 39.36 & 1.06 & 0.30 & 0.78 & 0.21 & 0.16 & 0.09 \\
$\mathrm{I}$ & 6.28 & 5.06 & 1.65 & 8.77 & 2.51 & 1.12 & 0.28 \\
$\mathrm{D}_{\text {mon }}$ & -2.30 & -1.20 & -0.38 & -1.20 & -0.26 & -0.19 & -0.04 \\
$\mathrm{D}_{\text {sur }}$ & -2.22 & -2.66 & -1.07 & -4.21 & -1.12 & -0.30 & 0.24 \\
$\mathrm{D}$ & -4.52 & -3.86 & -1.45 & -5.41 & -1.38 & -0.11 & 0.28 \\
$\mathrm{~B}$ & 1.76 & 1.20 & 0.20 & 3.36 & 1.13 & 1.01 & 0.56 \\
\hline \hline
\end{tabular}




\section{References}

[1] E. M. McCash, Surface Chemistry (Oxford University Press, 2002).

[2] R. E. A. Kelly, Y. J. Lee, and L. N. Kantorovich, J. Phys. Chem. B 109, 11933 (2005).

[3] M. Saldyka and Z. Mielke, Chem. Phys. 308, 59 (2005).

[4] P. S. Sedano, PhD Thesis (University of Girona, 2001).

[5] E. Sanchez-Garca, A. Mardyukov, A. Tekin, R. Crespo-Otero, L. A. Montero, W. Sander, and G. Jansen, Chemical Physics 343, 168 (2008), ISSN 0301-0104, theoretical Spectroscopy and its Impact on Experiment - (in honour of Sigrid D. Peyerimhoff).

[6] A. Travert, A. Vimont, J.-C. Lavalley, V. Montouillout, M. R. Delgado, J. J. C. Pascual, and C. O. Arean, J. Phys. Chem. B 108, 16499 (2004).

[7] H. Takahashi, K. Yuki, and T. Nitta, Fluid Phase Equilibria 194-197, 153 (2002).

[8] Q. Li, Z. Liu, J. Cheng, W. Li, B. Gong, and J. Sun, Journal of Molecular Structure: THEOCHEM 896, 112 (2009).

[9] M. Cases, G. Frenking, M. Duran, and M. Sola, Organometall. 21, 4182 (2002).

[10] C. F. Guerra, F. M. Bickelhaupt, J. G. Snijders, and E. J. Baerends, Journal American Chemical Society 122, 4117 (2000).

[11] C. Fonseca Guerra, F. M. Bickelhaupt, S. Saha, and F. Wang, The Journal of Physical Chemistry A 110, 4012 (2006), pMID: 16539424.

[12] Zhao, L. Jensen, and G. C. Schatz, Journal of the American Chemical Society 128, 2911 (2006), pMID: 16506770.

[13] G. Frenking, K. Wichmann, N. Fröhlich, C. Loschen, M. Lein, J. Frunzke, and V. M. Rayon, Coordination Chem. Rev. 238, 55 (2003).

[14] F. Bessac and G. Frenking, Inorg. Chem. 42, 7990 (2003).

[15] Y. Kan, Journal of Molecular Structure: THEOCHEM 805, 127 (2007), ISSN 0166-1280.

[16] Z. Zhu, M. Brynda, R. J. Wright, R. C. Fischer, W. A. Merrill, E. Rivard, R. Wolf, F. J. C., M. M. Olmstead, and P. P. Power, Journal American Chemical Society 129, 10847 (2007).

[17] M.-L. Bocquet, P. Sautet, J. Cerda, C. I. Carlisle, M. J. Webb, and D. A. King, J. Am. Chem. Soc. 125, 3119 (2003).

[18] A. Valcarcel, A. Clotet, J. M. Ricart, F. Delbecq, and P. Sautet, Surf. Sci. 549, 121 (2004).

[19] C. Morin, D. Simon, and P. Sautet, J. Phys. Chem. B 108, 5653 (2004).

[20] B. Wang, S. Gnther, J. Wintterlin, and M. L. Bocquet, New Journal of Physics 12, 043041 (2010).

[21] R. Kakkar, P. N. Kapoor, and K. J. Klabunde, The Journal of Physical Chemistry B 108, 18140 (2004).

[22] C. Morin, D. Simon, and P. Sautet, Surf. Sci. 600, 1339 (2006).

[23] O. Saengsawang, T. Remsungnen, S. Fritzsche, R. Haberlandt, and S. Hannongbua, J. Phys. Chem. B 109, 5684 (2005). 
[24] W. Klopper, J. G. C. M. van Duijneveldt-van de Rijdt, and F. B. van Duijneveldt, Phys. Chem. Chem. Phys. 2, 2227 (2000).

[25] M. Torrent, D. Mansour, E. P. Day, and M. K., The Journal of Physical Chemistry A 105, 4546 (2001).

[26] F. Cinquini, F. Delbecq, and P. Sautet, Phys. Chem. Chem. Phys. 11, 11546 (2009).

[27] J. Haubrich, D. Loffreda, F. Delbecq, P. Sautet, Y. Jugnet, C. Becker, and K. Wandelt, The Journal of Physical Chemistry C 114, 1073 (2010).

[28] K. H. Kim and Y. Kim, The Journal of Physical Chemistry A 112, 1596 (2008), pMID: 18220375.

[29] D. del Rio, G. Schubert, I. Papai, and G. A., Journal of Organometallic Chemistry 663, 83 (2002).

[30] S. F. Boys and F. Bernardi, Mol. Phys. 19, 553 (1970).

[31] F. Jensen, Chem. Phys. Lett. 261, 633 (1996).

[32] F. Jensen, Introduction to Computational Chemistry (John Wiley and Sons Ltd, 1999).

[33] F. B. van Duijneveldt, J. G. M. van Duijneveldt-van de Rijdt, and J. H. van Lenthe, Chem. Rev. 94, 1873 (1994).

[34] J. Sauer, P. Ugliengo, E. Garrone, and V. R. Saunders, Chem. Rev. 94, 2095 (1994).

[35] J. Scaranto, PhD Thesis, Venice (2007), URL http://venus . unive.it/molspectragroup/LowResolutionTi02/Ti0.htm.

[36] J. Scaranto and S. Giorgianni, The Journal of Physical Chemistry C 111, 11039 (2007).

[37] J. Scaranto and S. Giorgianni, Journal of Molecular Structure: THEOCHEM 858, 72 (2008).

[38] R. Dovesi, V. R. Saunders, C. Roetti, R. Orlando, C. M. Zicovich-Wilson, F. Pascale, B. Civalleri, K. Doll, N. M. Harrison, I. J. Bush, et al., CRYSTAL09 User's Manual, Università di Torino (Torino, 2010).

[39] J. Muscat, PhD Thesis (University of Manchester, 1999).

[40] P. C. Hariharan and J. A. Pople, Theoret. Chimica Acta 28, 213 (1973).

[41] A. D. Becke, J. Chem. Phys. 98, 5648 (1993).

[42] N. M. Harrison, X. G. Wang, J. Muscat, and M. Scheffler, Faraday Discuss. 114, 305 (1999).

[43] V. Swamy, J. Muscat, J. D. Gale, and N. M. Harrison, Surf. Sci. 504, 115 (2002).

[44] R. Lindsay, A. Wanderi, A. Ernst, B. Montanari, G. Thornton, and N. M. Harrison, Phys. Rev. Lett. 94, 246102 (2005).

[45] N. Wilson, J. Muscat, D. Mkhonto, P. Ngoepe, and N. Harrison, Phys. Rev. B 71, 075202 (2005).

[46] N. Wilson, S. Russo, J. Muscat, and N. Harrison, Phys. Rev. B 72, 024110 (2005).

[47] A. W. J. Muscat and N. M. Harrison, Chem. Phys. Lett. 342, 397 (2001).

[48] X.-B. Feng and N. M. Harrison, Phys. Rev. B 69, 035114 (pages 5) (2004), URL http://link.aps.org/abstract/PRB/v69/e035114. 
[49] M. Schmidt, W. R. II, P. G. Radaelli, K. Refson, N. M. Harrison, and S. W. Cheong, Phys. Rev. Lett. 92, 056402 (pages 4) (2004), URL http://link.aps.org/abstract/PRL/v92/e056402.

[50] F. Corà, M. Alfredsson, G. Mallia, D. Middlemiss, W. Mackrodt, R. Dovesi, and R. Orlando, in Principles and Applications of Density Functional Theory in Inorganic Chemistry II, edited by N. Kaltsoyannis and J. McGrady (Springer Berlin / Heidelberg, 2004), vol. 113 of Structure and Bonding, pp. 171-232, 10.1007/b97944, URL http://dx.doi.org/10.1007/b97944.

[51] G. Mallia, R. Orlando, M. Llunell, and R. Dovesi, in Computational Materials Science, edited by C. Catlow and E. Kotomin (IOS Press, Amsterdam, 2003), vol. 187 of NATO SCIENCE SERIES, III: Computer and Systems Sciences, pp. 102-121.

[52] J. Scaranto, G. Mallia, S. Giorgianni, C. M. Zicovich-Wilson, B. Civalleri, and N. M. Harrison, Surf. Sci. 600, 305 (2006).

[53] J. Scaranto, A. Pietropolli Charmet, P. Stoppa, and S. Giorgianni, J. Mol. Struc. 741, 213 (2005). 